\title{
Sobre a razão delirante
}

\author{
On raving reason
}

\author{
Cristiana Facchinetti \\ Psicanalista, doutora em teoria psicanalítica, \\ pesquisadora visitante do Departamento de Pesquisa da \\ Casa de Oswaldo Cruz (COC/Fiocruz) \\ Av. Brasil, 4036/sala 406 \\ 21040-361 Rio de Janeiro — RJ Brasil \\ cfac@coc.fiocruz.br
}

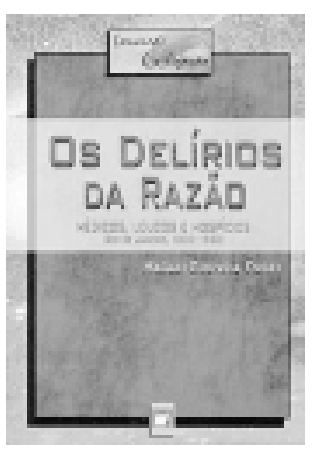

Magali Gouveia Engel Os delírios da razão: médicos, loucos e hospicios Rio de Janeiro, 1830-1930 Rio de Janeiro, Editora Fiocruz, 2001, 352p.

\begin{abstract}
A s reflexões sobre o campo médico-psiquiátrico no Brasil servem de instrumento para trazer à baila questões que envolvem dispositivos de poder e disciplina, na constituição de um saber que acabou por monopolizar a 'verdade' sobre a doença mental; além disso, tais considerações podem incidir sobre outros discursos, de modo a permitir verificar e, mesmo, desconstruir estratégias desenvolvidas ao longo de diferentes processos históricos. Afinal, "O discurso não é simplesmente o que traduz as lutas ou os sistemas de dominação, mas este porque, este por meio de que luta, o poder de que se busca apoderar-se" (Michel Foucault, A ordem do discurso, Paris, Gallimard, 1971, p. 12).

Desse modo, cada vez mais despontam historiadores e outros pensadores da cultura que se debruçam sobre a história das disciplinas que tratam do mental. O Império, por exemplo, passou a ser objeto de interesse para aqueles que indagam a respeito dos processos de consolidação do campo psi - campo que abarca as disciplinas que se debruçam sobre o psiquismo - e das abordagens sobre a loucura. Do mesmo modo, os períodos pós-colonial e as repúblicas são objeto de crescente atenção, como via de acesso às temáticas acerca do papel crítico que as novas metrópoles tiveram para a delimitação do campo psi, e o papel das políticas de saúde do Estado, das universidades etc. daí decorrentes. As atuais discussões antimanicomiais, as questões estabelecidas pela hipermedicalização do mal-estar psíquico, bem como as mais novas teorias genéticas, entre tantos outros objetos que confrontam o campo psi hoje, exigem uma realocação da arquitetura da saúde mental, assim como um novo tracejamento das disciplinas que tratam do irracional, da desrazão, do destempero, da vesânia, do delírio, das intensidades, do inconsciente e da pulsão em nossas bandas.

Dando um rumo singular a essas questões, Os delírios da razão: médicos, loucos e hospícios - Rio de Janeiro, 1830-1930, de Magali Gouveia Engel, é extremamente bem-vindo. Constitui material precioso para os que se interessam pela pesquisa genealógica e/ou os que intentam pensar o que se convencionou chamar de campo psi - as diversas disciplinas que trabalham com os fenômenos psíquicos hoje no Brasil.
\end{abstract}


Vale ressaltar que, além de captar os discursos e estratégias do poder disciplinar de um momento histórico crucial, a história social contada por Magali G. Engel é 'encorpada', trazendo uma abordagem onde as ruas do Rio de Janeiro (palco privilegiado das transformações do que começava a se delinear na sociedade brasileira a partir de meados do século XIX), seus personagens 'encarnados' e seus 'embates' surgem em meio ao desenvolvimento das cidades, à criação dos hospícios, às mudanças das relações de trabalho e ao crescente interesse do Estado pela saúde pública inserida como parte do projeto nacional. Nesta imbricação de caminhos, a vida e seus sons parecem fluir pelas ruas da cidade. Seus personagens ganham volume, cheiro e cor.

Com tal atmosfera, o livro de Magali Gouveia Engel encanta. Sua narrativa nos enlaça, quer por sua escrita, que muitas vezes resiste à pedra dura da linguagem científica, quer pela pesquisa, realizada de forma singular, mas sistemática. A autora soube reunir extensa documentação e informação bibliográfica para produzir um relato saboroso das idéias e vivências da loucura presentes na cidade do Rio de Janeiro, entre 1830 e 1930, período em que a loucura era apropriada e transposta paulatinamente para o universo da alienação mental.

As histórias dos personagens foram buscadas nas revistas de época, nos cronistas e memorialistas, nas fichas de observações clínicas e de laudos periciais. O livro começa com personagens das ruas do Rio de Janeiro do início do século XIX, famosos por sua vesânia, em uma narrativa que mostra a singularidade das concepções de loucura ali produzidas, difundidas e experimentadas. A autora sublinha, desse modo, "a existência histórica de diversas possibilidades de se conceber a loucura e de lidar com ela, distintas daquelas que caracterizariam sua transformação em doença mental, submetida ao controle do alienista" (p. 49), isto é, para além dos limites do conhecimento e do savoir-faire acadêmicos e científicos.

Com o surgimento da psiquiatria como campo autônomo da medicina, a criação do Hospício D. Pedro II e do curso de psiquiatria na Faculdade de Medicina na década de 1880 , as ações rumo ao alargamento de fronteiras para a intervenção especialista nos são reveladas através dos novos personagens que Magali G. Engel nos apresenta.

$\mathrm{Na}$ pesquisa sobre a trajetória dos psiquiatras brasileiros durante o século XIX, em sua luta pela transformação da loucura em objeto exclusivo de seu saber e prática, a pesquisadora recorreu a teses, artigos, memórias e discussões publicados em anais e em periódicos especializados em medicina mental; obras de psiquiatras e legistas; relatórios dos diretores de instituições psiquiátricas e judiciárias, além de fichas de observações clínicas e de laudos periciais.

Através dessas fontes, a autora demonstra que, ao fim do século XIX, os psiquiatras não buscavam mais as características visíveis do louco, oferecidas à superfície do olhar leigo para localizar a alienação mental; esta necessitava de investigação 'científica', através de instrumentos capazes de retirá-la de sua nova morada — os sutis sinais morfológicos e orgânicos: investigam-se os caracteres mórbidos da 
face segundo Chaillou e Mac Auliff; tomam-se medidas craniométricas, técnica de Lombroso (numa época em que as idéias de Lombroso já eram bastante contestadas nos meios científicos europeus), avaliando também reflexos da gustação e até dos aparelhos da vida vegetativa, completada por exames de urina, fezes, sangue e líquido cefalorraquiano. Avalia-se a atenção e a docilidade à hipnose, utilizase a prova Gudden de tolerância alcoólica, institui-se avaliação intelectual e mental por meio de linguagem falada e escrita, e de temperamento (através da fisionomia).

Vale também demarcar, neste processo, a aproximação da sexualidade com o crime e com a alienação mental, tão bem demonstrada pelos exemplos que Engel nos oferece nos capítulos dois e três: há um desfile de personagens que carregam, como causa de sua doença, estigma seu ou de seus antepassados: a sífilis, a referência de consangüinidade marital, a diferença de idade entre os cônjuges, a idade avançada do marido. Os familiares apelavam ao poder público pela interdição daqueles que demonstrassem desejos sexuais e afetivos incompatíveis com sua idade, gênero ou estado civil, considerado-os como "perversão do sentimento sexual". Até mesmo a inteligência e a cultura, no caso específico das mulheres, podiam incriminá-las.

Paradoxalmente, a ignorância, bem como a pobreza e a mendicância, passavam a ser vistas com desconfiança: a desrazão a elas implicada poderia justificar a interdição, fosse ela originária da fraqueza e da debilidade - a demência — ou decorrente dos excessos, do arrebatamento ou do furor - a loucura.

Tantos instrumentos refletem os tênues limites entre normalidade e anormalidade, apontando para a sua crescente invisibilidade e dificuldade de deciframento (esplendidamente traduzida por Machado de Assis em O alienista) e, paradoxalmente, a necessidade urgente de seu mapeamento e denúncia, com vistas a neutralizar suas características animalescas de excesso, de barbárie e de crime. Paulatinamente, o louco, até bem pouco tempo incluído, como diferença, na sociedade, vai dando lugar a uma doença cada vez mais perigosa aos ideais civilizatórios das cidades, exigindo encarceramento, exclusão.

A passagem da loucura para alienação mental nos é então demonstrada a partir de uma teia de relações que inclui médicos, higienistas brasileiros da virada do século, juristas, polícia, fazendo o leitor caminhar pelos mecanismos que acabam por 'inventar' o psiquiatra e sua instituição como a única competência que pode abarcar não mais a figura do louco, mas a abstração da alienação mental, figura desmaterializada, guardada nos recônditos escuros da mente, ameaçando sair. Os textos, principalmente médico-psiquiátricos, são aqui utilizados demonstrando a reivindicação de ampliação do espaço médico, sua ocupação sobre o campo social, e culminando, na década de 1920, com a constatação de que as estratégias e artifícios utilizados para legitimar e consolidar a intervenção e o controle da psiquiatria sobre todos os aspectos da saúde e da doença mentais, se não alcançaram a amplidão almejada, pelo menos garantiram muitos dos projetos formulados e defendidos por esse saber. 
O capítulo três estabelece também a trajetória histórico-conceitual da loucura à doença mental, dissecando, no discurso, os relatos encarnados apresentados, e estabelecendo, desse modo, o percurso por onde ela se desenrola do século XVIII até as primeiras décadas do século XX. Com este fim, autores como Michel Foucault, Robert Castel, Carlo Ginzburg, e também Maria Clementina Pereira Cunha e Jurandir Freire Costa são destacados, entre outros. Ainda, a segunda parte do livro dedica-se a analisar o enclausuramento a partir da abertura do Hospício D. Pedro II (capítulo 4) e do Hospício Nacional de Alienados (capítulo 5). Mais uma vez, a autora busca misturar o mundo das idéias - ao delinear e discutir o perfil disciplinador e o conteúdo excludente da prática asilar - com os odores, cores, ritmos e tilintar das chaves dos portões - algumas dimensões vivenciadas no cotidiano da população internada em tais instituições.

Assim, a presença encarnada dos personagens, bem como a pesquisa dos textos de época, se coloca como um 'outro' no texto de Engel, permitindo repensar o projeto psiquiátrico de normalização sob as trombetas dos ideais de civilização, ordem e progresso, de mudanças externas radicais e de internalização paulatina das individualidades.

Por mais que tenha sido legitimada a exclusão dos indivíduos 'fora da norma', por mais eficazes que tenham sido os discursos que ganharam estatuto de verdade e continuísmo, persistiram alternativas múltiplas de se viver e conviver com a loucura na cidade. Assim, tipos populares e loucos, como os apresentados pela autora, resistiram incólumes às investiduras higienizadoras das primeiras administrações republicanas, e continuaram a afrontar, com seus gestos, suas palavras e presença, tanto a elegância 'civilizada' da rua do Ouvidor no início do século XX, como a zona Sul da cidade do fim do mesmo século. Afinal, quem é desta cidade provavelmente tem alguma história pessoal do louco de sua rua para contar.

No meu caso, o livro de Engel trouxe das memórias da infância o Paulinho Cachaça, ou Paulinho Maluco, que, quando de bom humor, distribuía rosas para as meninas, moças e senhoras da vizinhança, e mesmo para os 'amigos' da rua; rosas que os mais velhos temiam, nos dizendo para evitar por serem "de algum despacho". Tínhamos medo de suas rosas, ao mesmo tempo que as recebíamos encantados, a idéia do despacho aumentando a força mágica que as flores da loucura pareciam ter. Brincávamos com Paulo; brigávamos com ele; mexíamos com seu burro-sem-rabo: risco de morte certa para nós, de ataques de fúria pavorosos. Lendo Os delírios da razão, tive saudades do Paulo Maluco, de uma rua mais humanizada do que essa em que hoje eu moro, onde o convívio com a diferença se fazia marcar por ele.

Os personagens encarnados que Magali nos traz à presença funcionam, assim, como uma polifonia de vozes que podem servir na reavaliação dos valores e na escolha de enunciações que viabilizem novas construções, nas quais o discurso hegemônico seja relativizado como critério de verdade.

Uma única crítica: para um conteúdo tão sedutor, faltou um invólucro adequado: a capa esqueceu de delirar. 